\title{
Design of an HIV Env antigen that binds with high affinity to antibodies against linear, conformational and broadly neutralizing epitopes within V1/V2
}

\author{
L Liao ${ }^{1 *}$, M Bonsignori ${ }^{1}$, K Hwang ${ }^{1}$, AM Moody ${ }^{1}$, R Park ${ }^{1}$, S Crawford ${ }^{1}$, H Chen ${ }^{1}$, TL Jeffries ${ }^{1}$, M Cooper ${ }^{1}$, X Lu ${ }^{1}$, \\ $\mathrm{R} \mathrm{De}^{1}, \mathrm{~N}$ Karasavvas${ }^{2}$, S Rerks-Ngarm ${ }^{3}$, S Nitayaphan ${ }^{4}$, J Kaewkungwal ${ }^{5}$, S Tovanabutra ${ }^{2}$, P Pitisuttithum ${ }^{6}$, \\ J Tartaglia ${ }^{7}$, F Sinangil ${ }^{8}$, J Kim ${ }^{2}$, NL Michael ${ }^{2}$, GD Tomaras ${ }^{1}$, Z Yang ${ }^{9}$, K Dai $^{9}$, M Pancera ${ }^{9}$, GJ Nabel ${ }^{9}$, JR Mascola ${ }^{9}$, \\ PD Kwong ${ }^{9}$, A Pinter ${ }^{10}$, S Zolla-Pazner ${ }^{11}$, MS Alam ${ }^{1}$ BF Haynes ${ }^{1}$
}

From AIDS Vaccine 2012

Boston, MA, USA. 9-12 September 2012

\section{Background}

The RV144 HIV-1 vaccine trial showed protection from HIV-1 acquisition with vaccine efficacy of $31.2 \%$. Study of the immune correlates demonstrated an inverse association of V1/V2 antibodies with infection risk. A key task for HIV-1 vaccine development is to improve the level of efficacy seen in the RV144 trial with subsequent vaccine designs.

\section{Methods}

E.A244 V1/V2 Env tags contains an N-terminal Ig leader sequence and C-terminal Avi- and His6-tags linked to the V1/V2 domain, was expressed in 293F cells and purified by nickel column. Binding of Tier 1 neutralizing mAb CH58 from RV144 vaccinees, V2 conformational mAb 697D and broadly neutralizing antibodies (bnAb) CH01 and PG9/PG16 to 33 HIV-1 gp140/gp120s and 12 HIV-1 V1/V2 scaffold Envs was tested by ELISA and surface plasmon resonance.

\section{Results}

Among 45 HIV-1/SIV Envs tested, E.A244 V1/V2 tags and E.A244 gp120 11 Env were the only Env antigens recognized by all three types of mAbs: CH58, 697D, and bnAbs CH01, and PG9/PG16. E.A244 V1/V2 tag bound

'Duke University Medical Center, Durham, NC, USA

Full list of author information is available at the end of the article
CH58 with a $\mathrm{Kd}$ of $0.33 \mathrm{nM}$ and 697D with a $\mathrm{Kd}$ of 117 nM. Although PG9 preferentially recognizes trimers, PG9 bound well to both E.A244 gp120 $11(\mathrm{Kd}=47.3)$ and E.A244 V1/V2 tags $(\mathrm{Kd}=83.3 \mathrm{nM})$. BnAb CH01 bound V1/V2 tags as well $(\mathrm{Kd}=334 \mathrm{nM})$. E.A244 V1/ V2 Env tags was also recognized by the unmutated ancestor antibodies (UAs) of CH58 with ELISA EC50 = $4.9 \mathrm{nM}$ and $\mathrm{CH} 01$ with EC50 $=\sim 1 \mu \mathrm{M}$. E.A244 V1/V2 tags and AE.gp70 V1/V2 scaffold were the best recombinant Envs for detection of plasma V1/V2 antibodies in RV144 vaccinees.

\section{Conclusion}

Recombinant E.A244 V1/V2 Env tags Env expresses linear as well as conformational determinants recognized by $\mathrm{V} 1 / \mathrm{V} 2 \mathrm{mAbs}$ and some of their UAs. This V1/V2 construct is a candidate immunogen to target RUAs and intermediate ancestors of V1/V2 antibodies to drive their induction.

\footnotetext{
Author details

'Duke University Medical Center, Durham, NC, USA. ²U.S. MHRP, Walter Reed Army Institute of Research, Silver Spring, MD, USA. ${ }^{3}$ Department of Disease Control, Ministry of Public Health, Nonthaburi, Thailand. ${ }^{4}$ Department of Retrovirology, US Army Medical Component, AFRIMS, Bangkok, Thailand. ${ }^{5}$ BIOPHICS, Faculty of Tropical Medicine, Mahidol University, Bangkok, Thailand. ${ }^{6}$ Faculty of Tropical Medicine, Mahidol University, Bangkok, Thailand. ${ }^{7}$ Department of Research and Development, Sanofi Pasteur, Swiftwater, PA, USA. ${ }^{8}$ Global Solutions for Infectious Diseases, South San
} 
Francisco, CA, USA. ${ }^{9}$ Vaccine Research Center/NIH, Bethesda, MD, USA.

${ }^{10}$ Public Health Research Institute Center, New Jersey Medical School,

Newark, NJ, USA. " Veterans Affairs New York Harbor Healthcare System,

Manhattan Campus, New York, NY, USA.

Published: 13 September 2012

doi:10.1186/1742-4690-9-S2-031

Cite this article as: Liao et al:: Design of an HIV Env antigen that binds with high affinity to antibodies against linear, conformational and broadly neutralizing epitopes within V1/V2. Retrovirology 2012 9(Suppl 2): O31.

Submit your next manuscript to BioMed Central and take full advantage of:

- Convenient online submission

- Thorough peer review

- No space constraints or color figure charges

- Immediate publication on acceptance

- Inclusion in PubMed, CAS, Scopus and Google Scholar

- Research which is freely available for redistribution

Submit your manuscript at www.biomedcentral.com/submit 